\title{
Combined familial adenosine deaminase and purine nucleoside phosphorylase deficiencies
}

\author{
A SHANON, ${ }^{*}$ S LEVIN,$*$ F HOLTZMAN,$\dagger$ F BROCK-SINAI, $\dagger$ AND A ABU-SAID $\ddagger$ \\ ${ }^{*}$ Department of Paediatrics A and Paediatrics Research Institute, Kaplan Hospital, Rehovot, $\dagger$ Haematology \\ Laboratories, Sheba Medical Centre, Tel Hashomer, and $\ddagger E l$ Nasser Children’s Hospital, Gaza, Israel
}

SUMmary We studied an Arab family in which two infants died of severe combined immunodeficiency caused by adenosine deaminase (ADA) deficiency. One infant had purine nucleoside phosphorylase (PNP) activity in the leucocytes only half that of normal. Four other infant siblings had previously died from infections before the age of 2 months. Hyperpigmented skin lesions preceded death in three cases. The healthy parents and three healthy siblings aged 4-9 years had varying degrees of both ADA and PNP deficiencies in both white and red cells. ADA deficiency was pronounced in two siblings, and mild in the third and in the parents, and PNP activity was severely deficient in one sibling, and moderately deficient in the parents and other two siblings, who were all well. Complete absence of ADA from white cells lead to the development of severe combined immunodeficiency, but even minimal residual ADA and PNP activity allowed maturation of the immune system with normal immune function.

Severe primary or hereditary combined B cell and $\mathrm{T}$ cell immune deficiency is rare, and unless treated with bone marrow transfusion (or fetal liver transplantation) is universally and rapidly fatal. Milder degrees of combined immune deficiency have been described in various syndromes, including Nezelof's syndrome, ataxia telangiectasia, chronic mucocutaneous candidiasis, short limbed dwarfism, Letterer-Siwe disease, Wiskott-Aldrich syndrome, and DiGeorge's syndrome. In most of these conditions the defect leading to the immune deficiency is unknown. A group of patients with severe combined immunodeficiency has, however, been described who have a congenital deficiency of certain enzymes that are part of the purine metabolic cycle. Deficiency of adenosine deaminase (ADA) has been found in at least $20 \%$ of cases of the autosomal recessive type of severe combined immunodeficiency, and deficiency of purine nucleoside phosphorylase (PNP) is associated with a selective cellular immune deficiency.

We report an Arab family in which four infants died within two months of birth from severe infections, particularly pneumonia and diarrhoea, which in retrospect could have been due to severe immune deficiency. Two infants who had been born recently and who had recurrent infections were studied and found to have severe combined im- munodeficiency with ADA deficiency, while varying degrees of both ADA and PNP deficiencies were found in other healthy members of the family (figure).

\section{Case reports}

CASE 1

A healthy male infant weighing $3000 \mathrm{~g}$ was born to healthy, unrelated parents. Three siblings, two boys and one girl aged 4-9 years, were alive and well, and

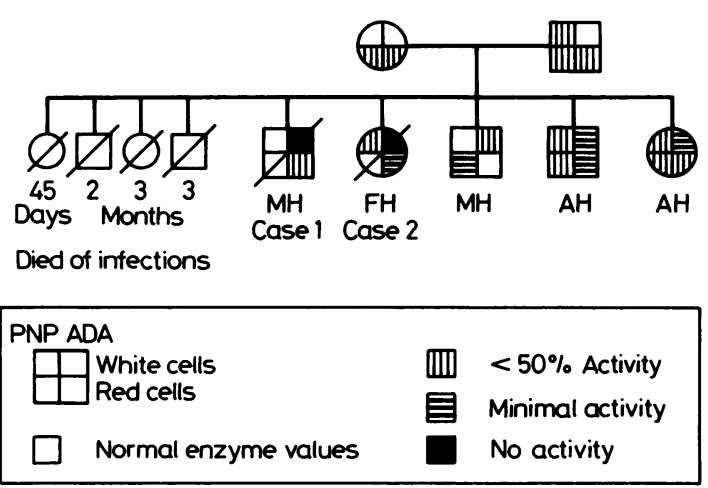

Figure Pedigree of Arab family with combined ADA and PNP deficiencies. 
four others had died within two months of birth of severe diarrhoea or pneumonia. The proband was examined at 7 days of age when there were no abnormal findings. Within a few weeks he developed a cough, and became cyanosed when feeding or crying. At the age of 1 month the parents noted hyperpigmented macules about $1 \mathrm{~cm}$ in diameter on the skin of his legs, groin, and arms. They had noticed similar spots on two other infants before their deaths, and so the infant was taken to the local doctor. The child did not appear to be particularly ill, had no fever or diarrhoea, although he did have mild cough. His weight was only $3200 \mathrm{~g}$ and there were a few rales at the bases of both lungs. After preliminary laboratory studies the baby (aged 6 weeks) was referred to the Kaplan Hospital with a diagnosis of possible severe combined immunodeficiency.

He weighed $4000 \mathrm{~g}$, and apart from a mild respiratory tract infection appeared comparatively well. There were several pigmented spots on his skin, and according to the parents these had become larger and more pronounced since birth. Histological examination of a biopsy specimen taken from one of the spots was not helpful. His haemoglobin concentration was $150 \mathrm{~g} / \mathrm{l}$, white cell count $6-9 \times 10^{9} / 1$, and lymphocytes $0 \cdot 18-0.90 \times 10^{9} / 1$. Liver function studies and concentrations of proteins, electrolytes, urea, creatinine, and complement were all within normal limits. An electrocardiogram was normal. Serial $x$ ray pictures of the chest showed progressive bilateral bronchopneumonia, which did not respond to treatment with antibiotics. No thymic shadow was seen on lateral $x$ ray pictures of the mediastinum. $X$ ray pictures of the skeletal system showed flaring of the costochondral junctions, and changes at the vertebrocostal junctions similar to those found in cases of ADA deficiency. ${ }^{12}$ Examination of the bone marrow showed severe lymphopenia. Table 1 gives a summary of the immunological studies. There was severe $\mathrm{T}$ cell deficiency (on one occasion there were $2 \% \mathrm{~T}$ rosettes, and on another $6 \%$ ) and a developing B cell deficiency. Delayed hypersensitivity skin tests were negative. Severe combined immunodeficiency seemed the most likely diagnosis, so it was decided to treat the infant by bone marrow transplantation. He suddenly developed severe respiratory distress, however, and died within a few weeks with bilateral pneumonia, severe diarrhoea, liver dysfunction, and renal failure. At necropsy generalised jaundice, patent liver ducts, and regional consolidation of both lungs were found; there was a rudimentary, minute thymus with some Hassall's corpuscles on histological section and small, shotty lymph nodes with diminished $\mathrm{T}$ zones.

Before death blood had been taken for specific lymphocyte enzyme studies but the results were only received later. When it become known that the infant indeed had deficiency of ADA in the white cells with low activity in the red cells, estimations of ADA and PNP activity were performed on the rest of the immediate family (table 2 ) using the technique of Beutler for ADA, ${ }^{3}$ and that of Kalckar for PNP. ${ }^{4}$

\section{CASE 2}

A sister of case 1, was referred at 13 days of age for immunological studies because of her family history. She weighed $3850 \mathrm{~g}$, did not appear to be ill, behaved normally and sucked well. No abnormali-

Table 1 Results of immunological studies-Case 1; normal values are given in parentheses

\begin{tabular}{lc}
\hline Test & Result \\
\hline Total lymphocyte count $\left(\times 10^{9} 1\right):$ & $0 \cdot 18-0 \cdot 9(>1 \cdot 5)$ \\
T cells (rosettes) & $2-6 \%(70 \%)$ \\
OKT3 (fluorescence activated & \\
cell sorting) & $1,28 \%(70 \%=>1 \cdot 2)$ \\
OKT4 (helper cells) & $1,18 \%(50 \%=>0 \cdot 75)$ \\
OKT8 (suppressor cells) & $1,17 \%(30 \%=>0 \cdot 45)$ \\
B cells (surface membrane & $10 \%(10-20 \%)$ \\
immunoglobulin) & Absent \\
Proliferative response of mononuclear cells: & Absent \\
To phytohaemagglutinin & \\
To concanavalin A & \\
Delayed hypersensitivity skin tests to & Negative \\
phytohaemagglutinin, mumps, and & Severe lymphopenia \\
Candida & $3 \cdot 5,4,3$ \\
Examination of bone marrow aspirate & $<0 \cdot 2,<0 \cdot 04,<0 \cdot 04$ \\
Immunoglobulin concentrations at 6,8, and 10 weeks of age $(\mathrm{g} / 1):$ \\
IgG & $0 \cdot 6,0 \cdot 95,<0 \cdot 12$ \\
IgA & $<0 \cdot 03$ \\
IgM & 53 U/ml (normal) \\
IgE (at 8 weeks only) & Normal \\
Interferon production during infections & Normal \\
White cell chemotaxis & Normal \\
Nitroblue tetrazolium test & \\
Phagocytosis & \\
\hline
\end{tabular}

Table 2 Estimations of $A D A$ and PNP activity in the blood of the members of the family being studied

\begin{tabular}{|c|c|c|c|c|}
\hline & \multicolumn{2}{|c|}{$\begin{array}{l}\text { Red cells ( } \mathrm{mM} / \mathrm{second} / \mathrm{g} \\
\text { haemoglobin) }\end{array}$} & \multicolumn{2}{|c|}{$\begin{array}{l}\text { White cells } \\
\text { (mM/hour } 110^{8} \text { cells) }\end{array}$} \\
\hline & $A D A$ & PNP & $A D A$ & $P N P$ \\
\hline Mother & $0.4,1.4$ & 10 & $0,3 \cdot 0$ & 26 \\
\hline Father & $0 \cdot 18$ & $7 \cdot 7$ & $4 \cdot 6$ & 28 \\
\hline Son (MH) & 0.57 & 3.9 & 1.97 & 44 \\
\hline Son $(\mathrm{AH})$ & 0.05 & 11 & 0.09 & 8 \\
\hline Daughter (AH) & $0 \cdot 17$ & 9.4 & 0.54 & 8 \\
\hline Case $1(\mathrm{MH})$ & $0 \cdot 2$ & 25 & 0 & 42 \\
\hline Case $2(\mathrm{FH})$ & $0 \cdot 2,0$ & 25,17 & 0,0 & 12,13 \\
\hline Normal ranges & $0 \cdot 7-1 \cdot 0$ & $20-30$ & $1 \cdot 5-9$ & $8-28$ \\
\hline
\end{tabular}


ties were found on physical examination and there were no pigmented spots. Her haemoglobin concentration was $130 \mathrm{~g} / \mathrm{l}$, white cell count $3.2 \times 10^{9} / 1$, and the lymphocyte count was only $0.45 \times 10^{9} / 1$. Immunoglobulin concentrations were within normal limits but $\mathrm{T}$ cell rosettes were not found. An $x$ ray picture of the chest showed mild lung opacities and a narrow mediastinum. ADA was absent from the patient's white cells and there was only low activity in the red cells. White cell PNP activity was about $50 \%$ of normal (table 2). Repeat investigations showed similar results, except that on this occasion ADA activity was also absent from the erythrocytes. HLA typing of the family was performed and one of the brothers was found to be a suitable bone marrow donor, although the ADA and PNP activities were low in both red and white cells. Arrangements were made for urgent bone marrow transplantation but the family withdrew consent and the infant died of bronchopneumonia.

\section{Discussion}

ADA and PNP are both enzymes that catalyse reactions in the purine catabolic pathway. ADA catalyses the conversion of adenosine to inosine, and PNP catalyses the conversion of inosine to hypoxanthine and of guanosine to guanine. Deficiency of ADA results in the accumulation of deoxyadenosine triphosphate in red and white cells, while in PNP deficiency there are raised concentrations of inosine, guanosine, deoxyinosine, and deoxyguanosine in the blood and increased secretion of their metabolites in the urine. Increased amounts of these metabolites are toxic to cells, with deoxyadenosine triphosphate being somewhat more toxic to lymphocytes than deoxyguanosine triphosphate. The latter has a specific toxic effect on T cells rather than $B$ cells, and therefore the immune deficiency is usually more extensive if ADA is deficient. ${ }^{5}$ The nature of the defect in ADA deficiency is still not clear, though it has been suggested that there might be a mutation in the gene for ADA leading to total deficiency and severe combined immunodeficiency, ${ }^{67}$ and genetic heterogeneity leading to partial deficiency. ${ }^{8}$ In PNP deficiency the genetic defect is almost certainly in the PNP gene locus itself, which is situated on the long arm of chromosome 14.?.

The correlation between ADA deficiency and immunodeficiency was first suggested in 1972 by Giblett $e t a t^{t}$ and three years later confirmed by Meuwissen $e t$ al. ${ }^{1}$ It has subsequently been shown that ADA deficiency is present in at least $20 \%$ of cases of the autosomal recessive type of severe combined immunodeficiency. ${ }^{7}$ Several reports have appeared, however, indicating that deficiency of ADA can occur without immunodeficiency, ${ }^{9-12}$ though it now seems that in most cases of ADA deficiency with no immune deficiency some minimal residual ADA activity is present in the cells. Jenkins et al described a healthy !Kung boy (a member of a black Bushman tribe in southern Africa) who had almost negligible amounts of ADA in both cells types. ${ }^{7910}$

Only about 20 patients with PNP deficiency have been described (Stoop JW, Zegers BJM, personal communication). Symptoms of immune deficiency may appear later in life; patients have been described who had normal immune function at birth, immunological deterioration occurring by the age of 2-3 years. The clinical picture suggests severely impaired $\mathrm{T}$ lymphocyte function, whereas B lymphocyte function is at least in part intact. No bone abnormalities have been found on radiography, but neurological abnormalities have been described. ${ }^{7} 13$

The first case in this family that we studied had no ADA activity in his white cells and diminished activity in his red cells, and the clinical picture and course were typical of severe combined immunodeficiency. The $\mathrm{T}$ cell deficiency was extreme, and the $\mathrm{B}$ cell deficiency became apparent at the age of 10 weeks. The high concentrations of IgM in the first two blood samples were unexpected and may have been caused by normal IgM production antenatally when theoretically ADA could have been supplied by the mother. In the samples of blood taken at 10 weeks of age IgM was not detected. Because the results of the enzyme studies were received after the baby's death, no efforts could be made to attempt temporary replacement treatment with irradiated red blood cells.

Severe combined immunodeficiency with ADA deficiency was diagnosed early in the second patient who could have benefited from bone marrow transplantation from her histocompatible brother, but further treatment was refused.

The results of the enzyme studies performed on the patient's family were remarkable in many respects (table 2). The father had low values of ADA and PNP in his red cells, but normal values in his white cells. At the time of writing he is leading a normal life with no evidence of immune deficiency. The mother, also well, had enzyme assays on two occasions; on the first, ADA values in her red cells were low and there was no activity in her white cells, and on the other occasion ADA activity was within normal limits. PNP activity in her red cells was low. These discrepancies are hard to explain and somewhat disturbing. The possibility of variations in technique because the repeat assays were done (albeit with normal controls) on different occasions 
were considered, as was the contamination of white cells by red cells during the assay. The latter is unlikely because of the normal ADA values in both cell lines, and minimal or even moderate contamination of cells could not have caused this increase on the second occasion. In addition, repeat assays done simultaneously on the mother and proband 2 showed good reproducibility. The son AH had extremely low ADA activity and moderately decreased PNP values in both red and white cells. The daughter AH also had low ADA and PNP values in both cell types. The son MH had low ADA activities, as well as extremely low PNP activity in his red cells. Like their parents, these three children lead normal, healthy lives and did not seem at the time of writing to have any defects of their immune systems. Cases 1 and 2 had severe ADA deficiency in both cell lines with normal PNP values.

It is difficult to explain the partial deficiency of two enzymes which, as far as we know, are unrelated except that they both play part in the purine metabolic cycle. It could be that there is some primary deficiency at some other point in this pathway, or a deficiency of a control protein for both enzymes. We can find no evidence for either hypothesis. It may be that the deficiency of one is secondary to the deficiency of the other. This is not likely, as in some family members PNP activity was normal despite deficient ADA activity, and in others both were deficient.

As far as we know no case report of combined ADA and PNP deficiency has been published. It seems from our study that even minimal residual amounts of ADA and PNP in white cells are sufficient to allow maturation and development of immune competence in some or all white cells. None of the subjects studied had complete PNP deficiency, but two infants with total ADA deficiency in their white cells developed severe combined immunodeficiency and died. For social reasons further investigations of this family has not been possible.

\section{References}

1 Meuwissen HJ, Pollara B, Pickering RJ. Combined immunedeficiency disease associated with adenosine deaminase deficiency. J Pediatr 1975;86:169-81.

2 Ratech H, Greco MA, Gallo G, Rimoin DL. Pathologic findings in ADA-deficient severe combined immunodeficiency. Am J Pathol 1985;120:157-69.

3 Beutler E. Adenosine deaminase in red-cell metabolism. In: Beutler E, ed. Manual of biochemical methods. 3rd ed. New York: Grune and Stratton, 1983:99-102.

4 Kalckar HN. Differential spectrophotometry of purine compounds by means of specific enzymes. J Biol Chem 1947;167:429-42.

5 Carson DA, Wasson DB, Lakow E, Kamatani N. Biochemical basis for lymphocyte dysfunction in ADA and PNP deficiency. Adv Exp Med Biol 1984;165 (B):133-9.

6 Giblett ER, Anderson JE, Cohen F, Pollara B, Meuwissen HJ. Adenosine deaminase deficiency in two patients with severely impaired cellular immunity. Lancet 1972;ii:1067-9.

7 Kredich NM, Hershfeld MS. Immunodeficiency diseases caused by adenosine deaminase deficiency and purine nucleoside deficiency. In: Stanbury JB, Wyngaarden JB, Fredrickson DS, Goldstein JL, Brown MS, eds. The metabolic basis of inherited disease. New York: Mcgraw-Hill, 1983:1157-83.

${ }^{8}$ Hirschhorn R. Inherited enzyme deficiencies and immunodeficiency: adenosine deaminase and purine nucleoside phosphorolase deficiencies. Clin Immunol Immunopathol 1986; 40:157-65.

9 Jenkins T. Red blood cell adenosine deaminase deficiency in a healthy Kung individual. Lancet 1973;ii:736.

10 Jenkins T, Robson AR, Nurse GT, Lane AB, Hopkinson DA. Deficiency of adenosine deaminase not associated with severe combined immunodeficiency. J Pediatr 1976;89:732-6.

11 Hirschhorn R, Roegner V, Jenkins T, Seaman C. Erythrocyte adenosine deaminase deficiency without immunodeficiency. Evidence for an unstable mutant enzyme. $J$ Clin Invest 1979;64:1130-9.

12 Borkowsky W, Gershon A, Shenkman L. Adenosine deaminase deficiency without immunodeficiency. Clinical and metabolic studies. Pediatr Res 1980;14:885-9.

13 Stoop JW, Zegers BJM, Hendrickx LH, et al. Purine nucleoside phosphorylase deficiency associated with selective cellular immunodeficiency. N Engl J Med 1977;296:651-5.

Correspondence to Professor Stanley Levin, Schneider Children's Hospital, Long Island Jewish Medical Center, New Hyde Park, New York. 11042, USA.

Accepted 15 January 1988. 